\title{
Risk of adverse events related to prolonged antibiotic use in patients diagnosed with Baggio-Yoshinari syndrome, or autochthonous Lyme-like disease, in Brazil
}

\author{
Álvaro Adolfo Faccini-Martínez ${ }^{[1],[2]}$ \\ [1]. Programa de Pós-Graduação em Doenças Infecciosas, Centro de Ciências da Saúde, Universidade Federal do Espírito Santo, Vitória, ES, Brasil. \\ [2]. Committee of Tropical Medicine, Zoonoses and Travel Medicine, Asociación Colombiana de Infectología, Bogotá, Colombia.
}

\section{Dear Editor,}

Lyme borreliosis (or Lyme disease) is a zoonotic tick-borne infection caused by the pathogenic species of the Borrelia burgdorferi sensu lato complex ${ }^{1}$. This disease is endemic in temperate regions of the northern hemisphere, namely North America, Europe and Asia, where anthropophilic ticks belonging to the Ixodes ricinus complex are major vectors of pathogen to humans ${ }^{1}$. Without antibiotic therapy, clinical manifestations of the disease occur in three stages, beginning with an early dermal infection, subsequent dissemination, and a late infection, commonly affecting the skin, joints, heart, or nervous system ${ }^{1}$.

Since the early 1990s, some researchers have argued in favor of a Brazilian Lyme-like disease (locally known as BaggioYoshinari syndrome [BYS]) in which patients have similar symptoms to those of Lyme borreliosis but differ in the clinical progression with recurrent and/or reactive symptoms, even in previously antibiotic-treated patients ${ }^{2}$. Although the etiological agent of this Brazilian syndrome has, to date, neither been isolated nor cultured from patients or clinical samples, pro-BYS researchers suggest that the etiological agent corresponds to B. burgdorferi sensu stricto ${ }^{2}$. They claim that the spirochete is in the process of adaptation to Brazilian vector ticks (Amblyomma spp. and Rhipicephalus spp. $)^{2}$. Moreover, they postulate that spirochetes associated with this syndrome have atypical morphologies (cysts or cell-wall-deficient bacteria) and exhibit genetic adjustments such as gene suppression ${ }^{2}$. Collectively,

Corresponding author: Álvaro Adolfo Faccini-Martínez.

e-mail: afaccini@gmail.com

Orcid: 0000-0002-1127-0132

Received 9 February 2019

Accepted 16 April 2019 these assumptions "could explain the protracted survival of these bacteria in hosts, beyond the induction of a weak immune response and the emergence of serious reactive symptoms" ${ }^{2}$. It is worthy of note that the above-mentioned hypotheses have never been proven by the scientific method.

On the other hand, pro-BYS researchers have instilled "autochthonous Lyme-like borreliosis" as a fact in the Brazilian medical field and promoted their own diagnostic criteria through enzyme immunoassay and/or Western blot (WB). Remarkably, these criteria do not follow those recommended by the Centers for Disease Control and Prevention (CDC), and a positive human case is diagnosed by obtaining a high number of bands rather than specific signature bands by $\mathrm{WB}^{2}$. In fact, our recent study found a high incidence of over-diagnosis of Lyme-like disease in Brazil from 2009 to 2016, represented by $99.8 \%$ of patients with serological results that do not meet the CDC criteria ${ }^{3}$. Furthermore, an alarming fact is that in patients diagnosed with secondary or tertiary stages of the syndrome, treatment with antibiotics and immunomodulatory drugs for at least three months is recommended ${ }^{2}$, which is not in accordance with the Lyme borreliosis guidelines ${ }^{1}$.

Brazilian public-health authorities should evaluate the real impact and risk for patients if they are to accept BYS as an autochthonous disease in their country. For this purpose, three issues should be considered: 1) in non-endemic areas or areas with low disease incidence (such as Brazil), serologic tests have poor positive predictive values and lead to a high proportion of false-positive results ${ }^{4} ; 2$ ) in patients with persistent symptoms attributed to Lyme disease, long-term antibiotic therapy does not have beneficial effects on health-related quality of life ${ }^{5}$; and 3 ) there is potential for serious adverse events (including death) related to unnecessary and prolonged antibiotic therapy in such patients ${ }^{6}$. 


\section{Acknowledgments}

I wish to thank Lesley Bell-Sakyi for proofreading and editing the manuscript.

\section{REFERENCES}

1. Steere AC, Strle F, Wormser GP, Hu LT, Branda JA, Hovius JWR, et al. Lyme borreliosis. Nat Rev Dis Primers. 2016;2:1-18.

2. Miziara CS, Serrano VA, Yoshinari N. Passage of Borrelia burgdorferi through diverse Ixodid hard ticks causes distinct diseases: Lyme borreliosis and Baggio-Yoshinari syndrome. Clinics. 2018;73:1-4.

3. de Oliveira SV, Faccini-Martínez ÁA, Cerutti Junior C. Lack of serological evidence for Lyme-like borreliosis in Brazil. Travel Med Infect Dis. 2018;26:62-3.

4. Lantos PM, Branda JA, Boggan JC, Chudgar SM, Wilson EA, Ruffin F, et al. Poor positive predictive value of Lyme disease serologic testing in an area of low disease incidence. Clin Infect Dis. 2015;61(9):1374-80.

5. Berende A, ter Hofstede HJ, Vos FJ, van Middendorp H, Vogelaar ML, Tromp M, et al. Randomized trial of longer-term therapy for symptoms attributed to Lyme disease. New Engl J Med. 2016;374(13):1209-20.

6. Marzec NS, Nelson C, Waldron PR, Blackburn BG, Hosain S, Greenhow T, et al. Serious bacterial infections acquired during treatment of patients given a diagnosis of chronic lyme disease United States. MMWR Morb Mortal Wkly Rep. 2017;66(23):607-9. 